\title{
Bargaining with Grandma $\longleftarrow$ o The Impact of the South African Pension on Household Decision-Making
}

\author{
Kate Ambler
}

\begin{abstract}
I examine how an exogenous change in individual income affects decisionmaking in the household. Using the age discontinuity in eligibility for the South African pension, I find that eligible women are 15 percentage points more likely to be the primary decision-maker in the household than noneligible women. This corresponds with a large increase in their share of household income. There are no parallel effects for men. Due to labor force withdrawal, male income does not increase with eligibility, suggesting that their status in the household is unchanged.
\end{abstract}

\section{Introduction}

The growing importance of cash transfers as an antipoverty tool in the developing world has highlighted the importance of understanding how households make decisions and allocate resources. Over the past three decades the theory of household resource allocation has evolved from unitary models that treat the household as a single entity (Samuelson 1956; Becker 1974; Becker 1981) to models that argue that preferences may vary within the household and that the distribution of bargaining power across household members will determine intrahousehold decision-making dynamics

\footnotetext{
Kate Ambler is a Research Fellow in the Markets, Trade, and Institutions Division at the International Food Policy Research Institute. She thanks Martha Bailey, Sarah Burgard, David Lam, Rebecca Thornton, Dean Yang, and seminar participants at the University of Michigan, the University of Cape Town, the Population Association of America Annual Meetings, the Midwest Economics Association Annual Meetings, the MASA conference in Durban, South Africa, and IFPRI for comments and guidance. She is grateful for the support of an NICHD training grant to the Population Studies Center at the University of Michigan (T32 HD007339). The data used in this article can be obtained beginning six months after publication through three years hence from Kate Ambler; address: International Food Policy Research Institute, 2033 K St. NW, Washington, DC 20006; email: k.ambler@cgiar.org.

[Submitted March 2014; accepted July 2015]; doi:10.3368/jhr.51.4.0314-6265R1

ISSN 0022-166X E-ISSN 1548-8004 ( 2016 by the Board of Regents of the University of Wisconsin System $\checkmark$ Supplementary materials are freely available online at: http://uwpress.wisc.edu/journals/journals/ jhr-supplementary.html

This open access article is distributed under the terms of the CC-BY-NC-ND license (http://creative commons.org/ licenses/by-nc-nd/3.0) and is freely available online at: http://jhr.uwpress.org
}

THE JOURNAL OF HUMANRESOURCES • $51 \cdot 4$ 
(Chiappori 1988; Chiappori 1992; Lundberg and Pollack 1993; Lundberg and Pollack 1994; Manser and Brown 1980; McElroy and Horney 1981). This shift has been supported by a growing amount of empirical evidence rejecting the predictions of the unitary model. However, these papers are largely based on the reduced form effect of income transfers on household outcomes, negating the unitary model but providing little specific evidence in support of alternative explanations. This paper addresses this gap in the literature by examining the effects of changes in income dynamics on direct measures of household decision-making, utilizing the age discontinuity in eligibility for the South African pension.

Empirical work on this topic has generally focused on rebutting the predictions of the unitary model by examining outcomes after exogenous changes in income. The unitary model has been rejected when it has been shown that these outcomes differ by the gender of the recipient. If the model held the identity of the recipient should not matter. For example, using the South African pension, Duflo (2003) finds that living with an eligible female leads to improvement in nutrition indicators of girls (but not boys) while male pension-eligibility has no effect on child nutrition. ${ }^{1}$ These papers provide convincing evidence that control of resources matters and have resonated in the policy community. In fact, due to studies that suggest that money given to or controlled by women is spent in more productive ways than money given to men, particularly for children's outcomes (Thomas 1990,1994; Duflo 2003), many cash transfer programs specifically target women.

This paper will use the South African pension to study how a permanent, large, and plausibly exogenous change in individual income affects the identity of the primary decision-maker in the household. This analysis is motivated by a standard collective approach where a household maximizes the weighted sum of its members' utility functions subject to a budget constraint (Chiappori 1988, 1992). The influence that each family member's preferences have on the ultimate allocation of resources (usually termed bargaining power in the empirical literature) is represented by the weight attached to his or her utility function. Existing theory and empirical evidence show that bargaining power is determined by a combination of many factors within the household including education, income, assets, and governmental policies that determine rights both within and outside of marriage. ${ }^{2}$ In this paper I will be concentrating on the role of just one of these factors, individual unearned income. The collective approach is a general framework that encompasses many more specific models of household behavior, including well-known models that specify bargaining solutions (Manser and Brown 1980; McElroy and Horney 1981). Because the goal of this paper is only to show that decision-making is moved by changes in the assumed components of bargaining power, the general framework is appropriate. ${ }^{3}$

Given that bargaining power is a composite measure of many components it cannot be directly measured. However, the expansive existing literature on the topic strongly links the concept of bargaining power to intrahousehold decision-making dynamics; bargaining power affects decision-making, which in turn affects household outcomes

1. Other examples include Lundberg, Pollack and Wales (1996) and Qian (2008).

2. See Doss (2013) for a review.

3. In fact, this discussion could apply to many models in which decision-making is moved by changes in the components of bargaining power, including those which allow for inefficient outcomes. 
(Lundberg and Pollak 1996; Duflo 2012; Browning, Chiappori, and Weiss 2014). Although decision-making in the household is a complex and difficult to measure process, it can be represented through survey questions, such as those used in this study, that ask respondents about which household members are involved in making decisions. These questions provide information about the decision-making process, which will allow for a concrete test of the hypothesis that changes in the components of relative bargaining power (in this case individual income) affect decision-making.

The structure of the pension is such that a vast majority of the black population qualifies by meeting an age requirement for eligibility, allowing for a clean analysis of the causal impacts of the pension using the age requirement to employ a regression discontinuity design. Using the first wave of the South African National Income Dynamics Survey (NIDS) collected in 2008, I find that age-eligibility for the pension results in women being 13 to 17 percentage points more likely to be the primary decision-maker in their household. Decision-making refers to day-to-day purchases or to a summary measure indicating decision-making in all four categories listed on the survey. There is no corresponding effect at the age of eligibility for men. The evidence suggests that this increase in decision-making power for women comes through a reduction in the decision-making power of older men and household disagreement about who is the decision-maker.

The argument that these changes in decision-making are evidence of increased bargaining power for eligible women is strengthened by an analysis of personal income share, defined as the percentage of household income that can be attributed to a certain household member. Personal income share is precisely the component of bargaining power that pension receipt should directly affect, and it is highly correlated with reported decision-making power for both men and women. Mirroring the results for decision-making, income share increases significantly with pension-eligibility for women but not for men. The concurrence of the income share and decision-making results is strong evidence that pension receipt is shifting bargaining power and subsequently decision-making dynamics in households with elderly women. The lack of changes in income share and decision-making for men is puzzling, given that men also receive the pension at the age of eligibility. However, I show that the pension income is offset by a corresponding reduction in male labor income. Male status in the household may not be affected by pension-eligibility.

I additionally find that the increase in female pension-eligibility translates into positive household-level impacts. These results, like those in Duflo (2003), seem to support the argument that transfers should be directed toward women and not men. However, the income share results suggest that there are no changes in household outcomes when men become pension-eligible, not because their preferences for expenditures necessarily differ but because the pension may not change their bargaining power. Therefore, there is no reason to expect changes in household outcomes with male eligibility. Indeed, an analysis of the 1993 data used in Duflo (2003) shows a similar pattern: increases in income share at pension-eligibility for women but not for men. These results suggest that large transfers can have complex impacts on household income patterns and that results such as those in Duflo (2003) should be interpreted carefully before drawing the policy conclusion that money is better directed to women than men.

This paper is related to a small number of other studies that also have examined how income is related to decision-making. Anderson and Eswaran (2009) find that, in 
Bangladesh, women's earned income has a larger impact on their participation in household decisions than unearned assets. Additionally, independent income generation affects decision-making power while working on a husband's farm does not. These results suggest that it is control of income, rather than contribution to income generation, that is most important in determining bargaining power. De la Brière and Quisumbing (2000) find that transfers from the Progresa conditional cash transfer program in Mexico had a negative effect on the husband being the sole decisionmaker in five of eight decision-making categories. However, all results are small, and because Progresa was not initially known to be permanent at the time of the evaluation, these results may not be generalizable to permanent increases in income. Additionally, because Progresa transfers were only made to women a comparison of the effects across genders is not possible.

Additional studies have considered whether providing women with access to financial services and employment increases their decision-making power. An evaluation of microfinance in India finds no effects on female decision-making or child health (Banerjee et al. 2015). However, a study that provided commitment savings accounts in the Philippines found that women with below-median decision-making power at baseline who were offered the savings account show improvements in an index of decision-making variables (Ashraf, Karlan, and Yin 2010). Additionally, Majlesi (2014) finds that improved employment opportunities for women in Mexico increases the share of household decisions made by wives. ${ }^{4}$

The paper proceeds as follows: Section II provides background on the pension and the data used in this paper. Section III discusses the identification strategy. Section IV provides the analysis of impacts on decision-making, Section V discusses the analysis of income share, and Section VI provides discussion and additional analysis. Section VII discusses the effects of household reorganization, and Section VIII concludes.

\section{Background}

\section{A. The South African Pension}

The government old age pension in South Africa is a generous, monthly cash transfer for older adults. Eligibility is determined by age and a means test. Women ages 60 and older are eligible for the pension. At the time the data used in this paper was collected, men did not become eligible until age $65 .^{5}$ The means test considers only the income of the individual and spouse and is such that the vast majority of the black population easily qualifies (even if labor income is considered) but the majority of whites and those with a separate pension do not (Lam, Leibbrandt, and Ranchhod 2006). Therefore, my analysis is restricted to the black population.

\footnotetext{
4. All the studies discussed in this paragraph and the previous one also draw a direct link between bargaining power and survey based decision-making questions.

5. In 2008 a law was passed to equalize the age of eligibility between men and women by 2010 . This was done in stages and the male age of eligibility immediately dropped to 63 (SouthAfrica.info, 2008). Because the law was enacted in mid-2008 and the data used in this paper were largely collected in the first half of 2008, the age of eligibility for men will be considered to be 65 for the purposes of this analysis. Fewer than 5 percent of the elderly men in the sample used in this study were interviewed in the second half of 2008.
} 
In 2008, 86 percent of age-eligible men and 92 percent of age-eligible women report receiving the pension (author's calculations from NIDS). The maximum benefit was R870 per month during most of the survey period, and was raised to R940 per month as work was concluding. Although the means test does allow for some phase out of benefits above certain income levels, in practice fewer than 15 percent of recipients in 2008 report receiving less than the maximum amount. ${ }^{6}$ This maximum of R870 was two times the monthly median per-capita household income of noneligible older women and 1.6 times the monthly median per-capita income of noneligible older men in the survey data-a substantial sum for most recipients.

Because the pension is large and widespread, there has been extensive research on its impact. Studies include analyses of pension takeup patterns and behavioral changes (Case and Deaton 1998), impacts on labor markets (Bertrand, Mullainathan, and Miller 2003; Posel, Fairburn, and Lund 2006; Lam, Leibbrandt, and Ranchhod 2006; Ranchhod 2006; Ardington, Case and Hosegood 2009; Abel 2013), child outcomes (Duflo 2000; Duflo 2003; Edmonds 2006), private transfers to the household (Jensen 2003), and household composition (Edmonds, Mammen, and Miller 2005; Hamoudi and Thomas 2014). ${ }^{7}$ This is the first study to directly examine how this change in income affects decision-making dynamics within the household.

\section{B. Data}

This paper utilizes data from the first wave of the National Income Dynamics Survey (NIDS) conducted in 2008. NIDS is a nationally representative survey of approximately 7,300 households and 28,250 individuals. Detailed information was collected both at the household and individual level through a household survey, individual adult surveys for people age 15 and over, and child surveys for children under 15. This data set is the first wave of a long-term panel study and Waves 2 and 3 are also available. However, certain changes (described in Section IV and online Appendix A) 8 in the data collection protocols between Wave 1 and Waves 2 and 3 make Wave 1 a more suitable data set to answer the questions of interest in this study. Therefore, although I present some analyses incorporating Waves 2 and 3, I focus on the original sample in Wave 1 as my main sample of interest.

The principal variables of interest are derived from the decision-making section of the individual adult questionnaire. Respondents were asked who in their household makes decisions in four categories: day-to-day household expenditures; large unusual purchases such as appliances, vehicles, or furniture; who is allowed to live in the household; and decisions about where the household should live. ${ }^{9}$ Interviewers note the person code of the main decision-maker, and if the decision-making is joint, they also note the person code of the second decision-maker.

6. The exchange rate over the survey period ranged from seven to eight South African Rand to the United States dollar.

7. There are also a number of studies addressing the impacts of the Brazilian public pension on education, health, and child labor. See Ponczek (2011) and de Carvalho Filho (2012).

8. All online appendices can be found at https://uwpress.wisc.edu/journals/pdfs/JHRv51n04_article04_ Ambler_Appendix.pdf.

9. I do not utilize a fifth category, where children should go to school, because it is asked only of respondents with school aged children. 
I define indicator variables for each decision-making category that are equal to one if the person is the primary decision-maker in the relevant category and zero otherwise. I also create an indicator variable denoting if the person is the primary decision-maker in all four categories. I consider someone to be the primary decision-maker if everyone in the household who answered the question listed this person as the main decision-maker. The percentages of older women and men who are the primary decision-maker in each category and in all four categories are listed in the bottom panel of Table 1. Both older men and older women are highly likely to be the primary decision-maker in their households. The results in this paper are robust to defining the decision-making variables using only the self reports of the person in question.

These decision-making variables are a discrete representation of a complex underlying process, and it is therefore important to understand how they map to the collective framework described in Section I. Each household member's bargaining power in the collective model can be modeled as a continuous latent variable. The decision-making variable, as a representation of that bargaining power, will be equal to one if an individual's bargaining power passes a certain threshold and zero otherwise. The content of the question (identity of the primary decision-maker) is such that the threshold is an important one but the binary nature of the questions does not allow the analysis to identify small changes in bargaining power or changes for those who were very far away from the threshold.

Given that these variables are by necessity a subjective and simplified measure of abstract household behavior, it is useful to consider in more detail whether they actually measure individual capacity to influence household decisions. One concern is that different types of people within the family may interpret these questions differently. For example, the data shows that family members do not always agree on the identity of the decision-maker. I address this by defining someone to be the decision-maker only if everyone in the household agrees.

An additional concern is that it is not immediately clear how to interpret the different categories of decision-making. What does it mean if someone is listed as the decisionmaker in one category but not another, and how do these categories interact with each other? Although the survey does not directly answer these questions, it is important to note the responses are highly correlated across categories. Ninety percent of respondents are indicated to be the decision-maker in either zero or all four categories. In addition to this observation, I approach this issue directly by examining both the patterns related to the individual categories and cases where an individual is indicated to be the primary decision-maker in all four categories. By studying cases where everyone agrees and where individuals are named in all four categories, it is difficult to argue that the indicated person does not hold important influence over household decisions. This approach then comes with the caveat that I will identify changes in the person with substantial influence over the household but may miss more subtle changes in household dynamics. ${ }^{10}$

10. An additional issue is that different circumstances may affect how people answer this question. For example, if pension receipt changed the way in which respondents interpreted the question in a way that was not consistent with changes in decision-making, this could affect the results of my analysis. Thus, the results should be interpreted with this in mind. 
Table 1

Summary Statistics for Adults Aged 50 to 75

\begin{tabular}{|c|c|c|c|c|}
\hline & \multicolumn{2}{|c|}{ Women } & \multicolumn{2}{|c|}{ Men } \\
\hline & $\begin{array}{l}\text { Not } \\
\text { eligible }\end{array}$ & Eligible & $\begin{array}{l}\text { Not } \\
\text { eligible }\end{array}$ & Eligible \\
\hline \multicolumn{5}{|l|}{ Demographics } \\
\hline Age (mean) & $54.3(2.8)$ & $66.8(4.5)$ & $55.9(4.2)$ & $69.2(3.0)$ \\
\hline Household size (mean) & $5.1(3.0)$ & $5.1(3.0)$ & $4.6(3.0)$ & $5.3(3.2)$ \\
\hline Years of schooling (mean) & $4.3(4.0)$ & $2.8(3.5)$ & $4.9(4.1)$ & $2.8(3.4)$ \\
\hline Rural (percent) & 63.4 & 71.7 & 55.7 & 75.3 \\
\hline Married (percent) & 46.7 & 32.7 & 73.8 & 78.8 \\
\hline $\begin{array}{l}\text { Presence of child under fifteen } \\
\text { (percent) }\end{array}$ & 71.9 & 73.8 & 60.1 & 69.2 \\
\hline $\begin{array}{l}\text { Presence of child under five } \\
\text { (percent) }\end{array}$ & 42.7 & 40.9 & 32.0 & 43.0 \\
\hline $\begin{array}{l}\text { Presence of man (woman) } \\
50+\text { (percent) }\end{array}$ & 35.6 & 28.3 & 42.4 & 70.2 \\
\hline Presence of woman 18-49 (percent) & 51.6 & 53.9 & 56.3 & 58.4 \\
\hline Presence of man 18-49 (percent) & 45.1 & 45.1 & 35.2 & 40.9 \\
\hline \multicolumn{5}{|l|}{ Income and employment } \\
\hline Employed (percent) & 42.9 & 16.3 & 54.1 & 21.0 \\
\hline Per-capita hh income (median) & 428 & 482 & 514 & 570 \\
\hline Personal income (median) & 635 & 940 & 870 & 870 \\
\hline $\begin{array}{l}\text { Personal income as percent } \\
\text { of total hh income (median) }\end{array}$ & 31.5 & 47.9 & 36.0 & 39.8 \\
\hline \multicolumn{5}{|l|}{ Pension receipt } \\
\hline Received pension (percent) & 9.2 & 90.8 & 8.2 & 85.0 \\
\hline $\begin{array}{l}\text { Amount received (median, } \\
\text { conditional on receipt) }\end{array}$ & 885 & 870 & 920 & 870 \\
\hline \multicolumn{5}{|l|}{ Is primary decision maker for } \\
\hline Day-to-day purchases (percent) & 60.8 & 67.7 & 55.9 & 62.0 \\
\hline Large, unusual purchases (percent) & 57.9 & 64.9 & 64.1 & 66.5 \\
\hline Who can live in household (percent) & 55.7 & 64.6 & 68.4 & 71.7 \\
\hline Where household lives (percent) & 55.4 & 64.3 & 69.5 & 71.0 \\
\hline All four categories (percent) & 53.1 & 61.6 & 53.5 & 58.8 \\
\hline Observations & 932 & 862 & 830 & 279 \\
\hline
\end{tabular}

Notes: Author's calculations from 2008 NIDS. Standard deviations for means are in parentheses. Number of observations is based on black individuals aged 50-75 with nonmissing values for decision-making on day-today purchases, which is the main regression sample. All money amounts are in South African rand, the exchange rate varied from 7 to 8 rand to the U.S dollar over the survey period. Employment is defined as working in any capacity including casual labor, self employment, and own farm labor. Personal income is any income that can be attributed directly to the individual. Decision-making variables are dummy variables for whether everyone in the household agrees that the individual is the primary decision-maker in that category. 
Table 1 presents summary statistics for the sample of older adults that will form the main analysis sample broken down by gender- and pension-eligibility. Differences in several key variables including years of schooling, residence in a rural area, percent married, and employment status are evident. For example, 63 percent and 72 percent of noneligible and eligible women live in rural areas and 43 percent and 16 percent of noneligible and eligible women are employed. These differences alone do not invalidate the empirical strategy; pension-eligible adults are older than almost-eligible adults, and these statistics reflect age trends. Consequently, the analysis will control for age, estimating a break in a smooth trend at the age of eligibility.

Table 1 also shows that elderly adults tend to live in extended family households; more than half live with a younger woman and a lower but meaningful fraction live with a younger man. Many also live with an older adult of the other gender, and that number is higher for men than women. The presence of other adults in these households makes the analysis of decision-making particularly interesting because the options for the decision-maker are greater than just the older adult and spouse. Studies of decision-making often are concentrated on spouses but the presence of multigenerational households in this sample and the format of the survey question allows for the examination of decisionmaking across a variety of household members.

\section{Identification Strategy}

Although a simple comparison of those who receive the pension with those that do not would confound the impacts of the pension with systematic differences between the two groups, the age requirement for eligibility provides a discontinuity in receipt of the pension that allows for estimation of its causal impact at the age of eligibility using a regression discontinuity design. Because the means test for eligibility is not binding for the vast majority of black South Africans, this paper (and other studies on the pension) considers only the age-eligibility rule when determining pension impacts. My analysis compares people who are age-eligible for the pension to those who are almost eligible. The identification assumption underpinning the results is that individuals just below pension-eligibility differ from those just above eligibility only through the effect of the pension itself. Even though age trends independent of the pension are expected in many outcome variables (including household decision-making), these trends should not result in large changes right at the age of eligibility. Therefore, discontinuous changes in outcomes that occur at age 60 for women and age 65 for men can be causally attributed to the pension.

The plausibility of the identification assumption is greater the more similar are the individuals included in the analysis. Consequently, as in Edmonds (2006) I limit my estimation sample to black adults who are 50 to 75 years old. Identification still may be threatened if there are discontinuities in individual and household characteristics other than pension receipt that might be driving the results. An example of this would be if another large social program were implemented with the same eligibility rules. 
Although there are several other government grant programs in South Africa, none of them are similar to the pension in ways that might invalidate the identification strategy (Duflo 2003; McEwan, Kannemeyer, and Woolard 2009).

An additional concern with regression discontinuity analysis centers on possible manipulation of the variable used to determine eligibility. If people are aware of the cutoff for a program they may be able to alter their behavior in such a way that will ensure they are above the cutoff, thereby invalidating the assumption that people just above and below the cutoff point are similar. However, although older South Africans could attempt to portray themselves as older than they are in order to become eligible sooner, there is no evidence that this behavior is widespread. Additionally, there is no reason why they also would misreport their age on the NIDS survey. Online Appendix Figure 1 shows the number of observations per age for both men and women. If people were overreporting their age to accelerate eligibility, there should be relatively more people just above the cutoff compared to just below. No such pattern is apparent.

A greater worry is that the pension may induce households to reorganize, and that changes that are attributed to the pension may actually be characteristics of these new households. Existing work (Edmonds, Mammen, and Miller 2005; Hamoudi and Thomas 2014) suggests that that the pension does have some effect on household composition. Therefore, it is important to understand whether these changes are causing the results. These issues will be given careful attention in Section VII, and the balance of the evidence supports the argument that changes in household composition are not driving the results.

In order to validate the use of the age discontinuity, I first must establish that the pension system works as it is described - that is, that there is actually a discontinuity in receipt of the pension at age 60 for women and age 65 for men. The NIDS survey asked each adult individually whether he or she had received the government pension in the past month. The averages of these responses in Table 1 show that the likelihood of receiving the pension increases dramatically with age-eligibility, from 9 percent to 91 percent for women, and from 8 percent to 84 percent for men. Figure 1 shows the discontinuity in pension receipt graphically, plotting the average receipt by age and the regression line of pension receipt on age calculated on both sides of eligibility. This analysis is repeated in a regression framework in online Appendix Table 1. ${ }^{11}$ Although there is some slippage in pension receipt, the discontinuity is unmistakable. Some of the slippage may be due to age misreporting but there is also evidence that some ineligible people are able to receive the pension. This is especially true for men, given that the age of male eligibility was largely considered unfair, and the survey was conducted just months before the threshold was lowered. Indeed the discontinuity in pension receipt, while strong, is smaller for men than for women. While the smaller threshold does not invalidate the identification strategy, it does reduce the statistical power of the analysis.

11. The regression specification is the same as Equation 1 (to be described in the next paragraph) with pension receipt as the dependent variable. 
Panel A: Women

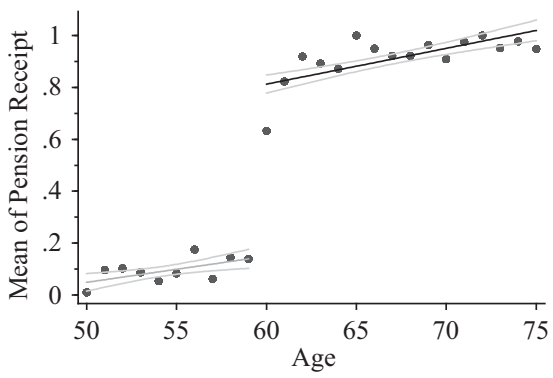

Panel B: Men

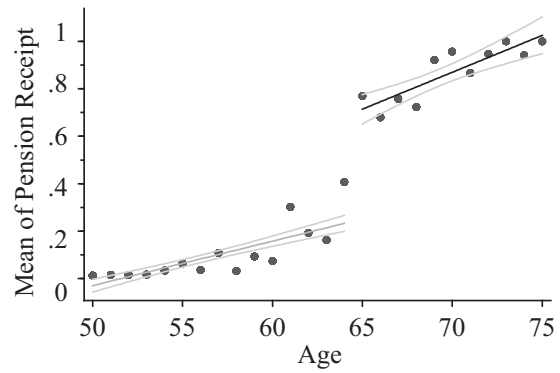

\section{Figure 1}

\section{Pension Receipt by Age}

Notes: Sample is individuals aged 50 to 75, women in Panel A and men in Panel B. Scatterplots are unweighted means of Y-axis variable by age in years. Unweighted OLS regression lines of Y-axis variable on age are estimated on either side of the discontinuity (age 60 for women and age 65 for men). Ninety-five percent confidence intervals are shown around the regression lines. Y-axis variable is a dummy variable for pension receipt.

In the main results of the paper, I leverage this discontinuity by estimating the following linear probability model on the sample of females aged 50 to 75 :

$$
\begin{aligned}
\text { DecisionMaker }_{i j}= & \alpha_{f} \text { Eligible }_{i j}+\theta_{1} \text { EligibleMale }_{j}+\theta_{2} \text { OlderMale }_{j} \\
& +\gamma\left(\text { Age }_{i j}\right)+\text { SControl }_{i j}+\varepsilon_{i j}
\end{aligned}
$$

where Eligible is an indicator for whether a woman $i$ in family $j$ is pension-eligible. EligibleMale $_{j}$ and OlderMale $_{j}$ are indicators for the presence of a pension-eligible male or any male aged 50 or older. $\left(A g e_{i j}\right)$ is a polynomial in the age of the woman that controls for smooth age trends in the outcome variable. The inclusion of a polynomial to control for trends in the variable that determines treatment is one standard method in the regression discontinuity literature (Lee and Lemieux 2010). Throughout the paper I will show specifications utilizing linear, quadratic, and cubic age trends, and the main results are robust to all three choices. ${ }^{12}$

Included controls are a set of indicators for educational attainment, the number of household members aged $0-5,6-14,15-24$, and 25-49, and rural status. Robust standard errors are clustered at the household level, and all regressions make use of survey poststratification weights. ${ }^{13}$ I estimate the analogous model for the male sample controlling instead for the presence of an eligible female and an older female. The coefficient $\alpha$ on the eligibility indicator is the coefficient of interest. It is an estimate of the impact of pension-eligibility on the decision-making outcome variable at the age of eligibility.

12. Gelman and Imbens (2014) show that regression discontinuity results obtained with higher order (cubic and above) polynomials are sensitive to the chosen degree of the polynomial and can lead to specious findings with a higher probability than linear or quadratic specifications.

13. The results are robust to the exclusion of the weights. 


\section{Impacts of Pension-eligibility on Decision-making}

\section{A. Individual Level Decision-Making Analysis}

As a first step in my analysis, in Figure 2, I graph the means of the day-to-day decisionmaking variable by age separately for women and men and, as in Figure 1, I also plot the regression line of decision-making on age estimated separately on either side of the discontinuity with 95 percent confidence intervals. These graphs are illustrative of the main result of this paper. Despite a pronounced negative age trend in decision-making for elderly women, there is a large jump upward at age 60, a difference that is statistically significant even given wide confidence intervals. The same is not true for men; the estimated effect is small and does not approach statistical significance. Despite this large jump in the regression lines for women, there is quite a bit of noise in the raw means. Online Appendix Figure 2 shows the same data but with the means smoothed over twoyear (instead of one-year) age bins. This smoothing reduces the noise significantly, lending further credence to the estimated discontinuity for women.

Next, I address the question of how the pension impacts the identity of the primary decision-maker in a regression framework to provide precise estimates of the effects. Table 2 presents the results from the estimation of Regression Model 1 described in Section III. This is an individual-level analysis and includes all black men and women aged 50 to 75 . The dependent variable in Columns 1-4 is a binary variable equal to one if everyone in the household agrees that the person is the primary decision-maker for day-to-day purchases, and in Columns 5-8 it is a binary variable equal to one if everyone in the household agrees that the person is the primary decision-maker in all four decision-making categories. Columns 1 and 5 include a linear trend in the age of the person, Columns 2 and 6 utilize a quadratic trend, and Columns 3 and 7 are estimated with a cubic trend. Columns 4 and 8 also use a cubic trend and additionally include control variables. The results are in Panel 1 for women and Panel 2 for men. At the bottom of the table, I report $p$-values on tests for the equality of the female and male eligibility coefficients.

The South African pension has a large and statistically significant impact on the decision-making power of eligible women, a result that is robust to the inclusion of linear, quadratic, or cubic age trends. Focusing on the results using the cubic age trend, the results in Column 3 show that eligible women are 16.7 percentage points more likely to be the primary decision-maker for day-to-day purchases. The estimated effect is an economically significant 26 percent of the sample mean. The coefficient is not sensitive to the addition of control variables, dropping only slightly, to 15.3 percentage points, in Column 4. The stability of this coefficient further strengthens the causal identification in this analysis: If the effects were being driven by other differences around the age of eligibility, the addition of control variables should have significantly attenuated the coefficient on eligibility. The impact of pension-eligibility on decision-making for all four categories is similar, 13 to 17 percentage points compared to a slightly lower sample mean. Analysis of cases where the dependent variable is primary decision-maker for large, unusual purchases, where the household lives, and who can live in the household shows similar effects of pension-eligibility (online Appendix Table 2). The consistency of this result across decision-making categories and for those who are the decisionmaker in all categories reinforces the claim that these results are evidence of a real shift in women's ability to influence household decisions. 

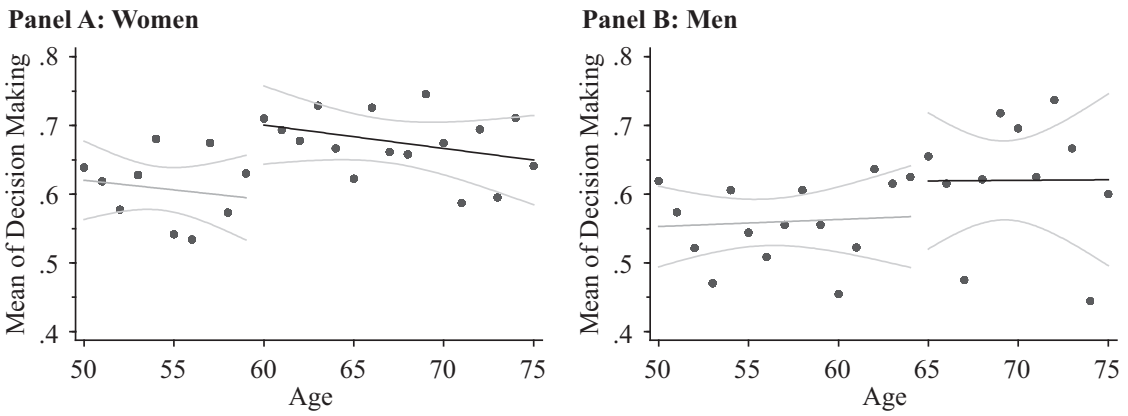

\section{Figure 2}

\section{Primary Decision-making for Day to Day Purchases by Age}

Notes: Sample is individuals aged 50 to 75, women in Panel A and men in Panel B. Scatterplots are unweighted means of Y-axis variable by age in years. Unweighted OLS regression lines of Y-axis variable on age are estimated on either side of the discontinuity (age 60 for women and age 65 for men). Ninety-five percent confidence intervals are shown around the regression lines. Y-axis variable is a dummy variable for whether or not everyone in household agrees that individual is the primary decision-maker for day-to-day purchases.

No significant effects of pension-eligibility are present for the male subsample in Table 2, and given that the estimated coefficients are negative, there is not even suggestive evidence of a positive effect. The coefficients on male eligibility are all statistically different from the coefficients on female eligibility at the 5 percent level. They are also more sensitive to changes in specification (altering the age trend and adding control variables) than the coefficients on female eligibility. There are some significant results for the categories of where a household can live and who can live in that household but they are not robust across specifications and are consistently negative. Additionally, no effect, positive or negative, is visible in graphical analysis of these other trends. While it should be acknowledged that the lack of impact in the male sample could be due to reduced power from a smaller sample size and weaker discontinuity, these results, combined with the fact that Figure $2 b$ shows no true discontinuity, make it unlikely that there is any true effect, positive or negative, for men. ${ }^{14}$ Possible explanations for this asymmetry in results between men and women will be discussed in Section V. ${ }^{15}$

The regressions presented in Table 2 differ from the regression lines shown in Figure 2 in that the polynomial in age is not allowed to vary on either side of the age cutoff.

14. If the ability of men to influence household decisions is changing, it is not by a large enough amount to change the measures of decision-making used in this paper.

15. I also find no impact on the likelihood of being the secondary decision-maker for either men or women. Additionally, to draw a comparison with other papers that utilize survey questions with a more common format that focuses on sole and joint decision-making, in results not shown I also create and analyze variables that indicate whether the person in question is the sole decision-maker, a joint decision-maker, or a joint-primary decision-maker. This analysis follows the same pattern for men as in the main analyses. The positive effect for women is fully concentrated in the sole decision-maker variable (there are no increases in women as jointprimary decision-makers with pension-eligibility). 


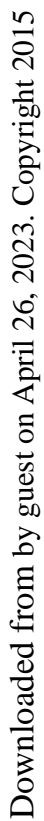

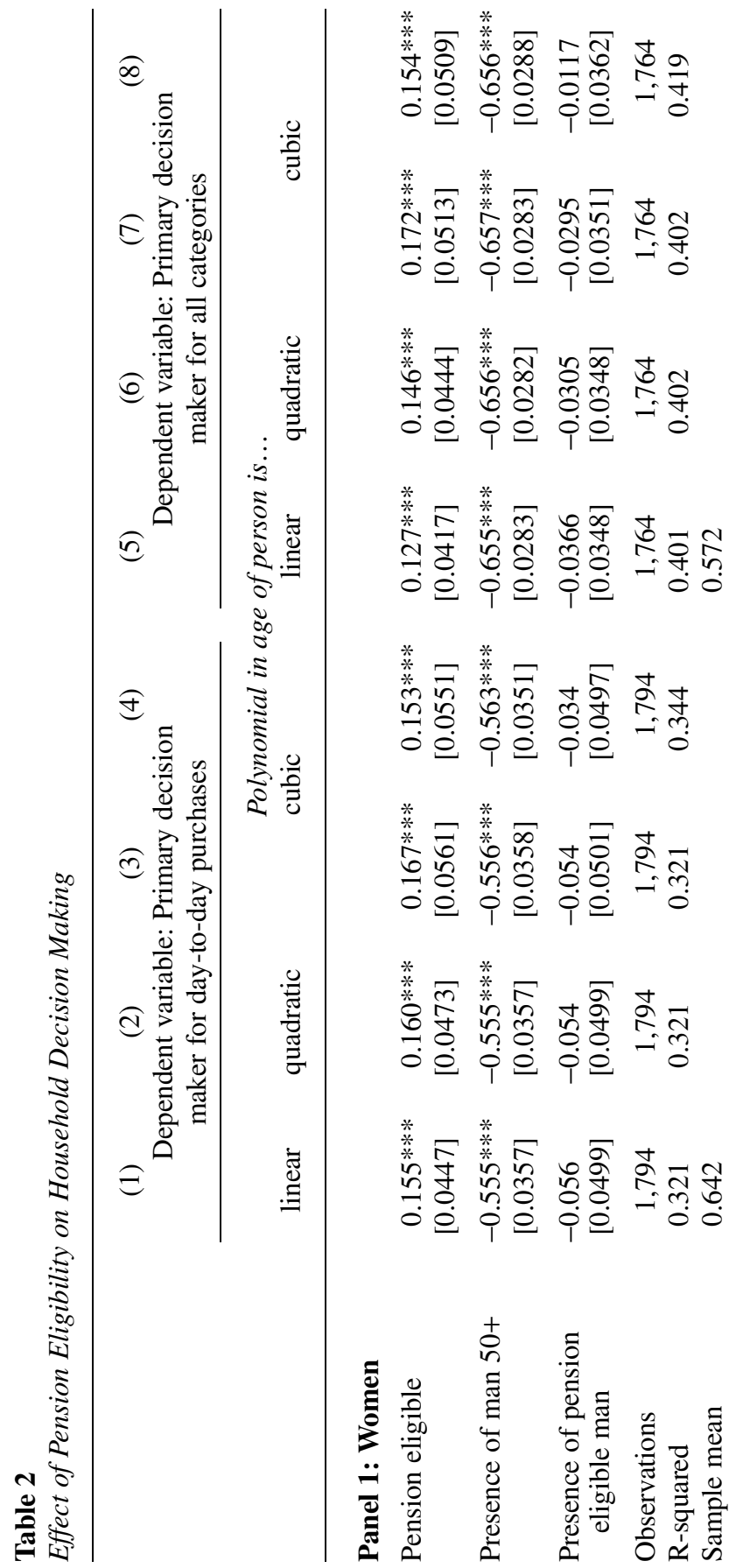




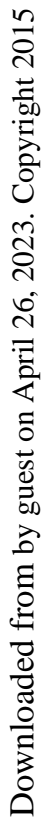

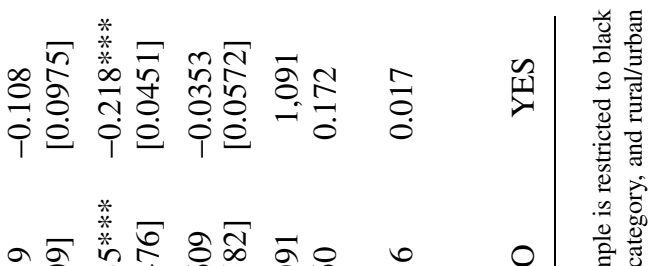

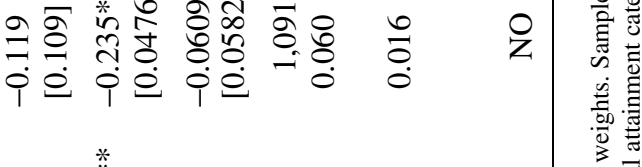

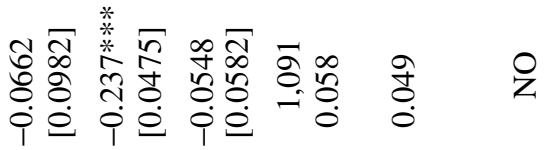

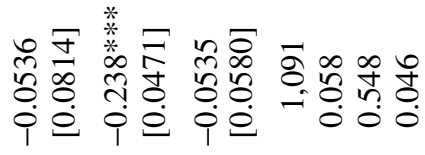

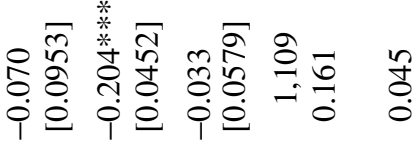

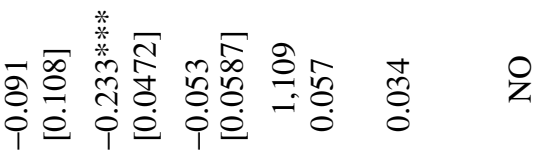

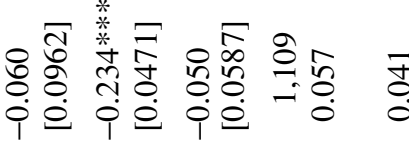

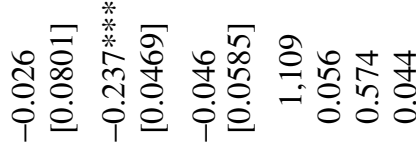

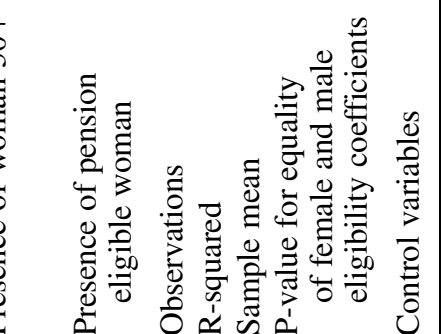


Allowing this variation would result in a more flexible specification and is often considered to be the preferred method of estimating regression discontinuity models. However, this type of specification is more data-intensive and can reduce power, especially when working with smaller sample sizes and if the true slope is the same on either side (Lee and Lemieux 2010). In online Appendix Table 3 I replicate Table 2 but allow the polynomial to vary. The main results for women are similar in magnitude to the results in Table 2 but precision is reduced; the coefficient on female eligibility is only statistically significant when using a linear age trend for decision-making over day-to-day purchases and a linear or quadratic age trend for decision-making in all four categories.

The results presented in this section using the NIDS Wave 1 data are strong evidence that female pension-eligibility affects female decision-making power. Given the availability of similar measures in NIDS Wave 2 and 3, a key robustness check is to consider whether the same patterns are repeated in the later samples. This analysis is presented in Table 3, focusing on the category of decision-making for day-to-day purchases. Columns 1 through 4 show the results from Wave 2 and Columns 5 through 8 show the results from Wave 3. Panel 1 presents the results for women and Panel 2 for men. All sample and variable construction is as in Table 2.

Table 3 shows that the results are not robust to using the Wave 2 and Wave 3 samples. The coefficients across specifications for female eligibility in Wave 2 are positive but much smaller than in Wave 1 and not statistically significant. The Wave 3 coefficients are also positive and are somewhat larger but statistically significant only for the linear age trend specification (Column 5). The coefficients for male eligibility are positive in Wave 2 and negative in Wave 3, and do not approach statistical significance in either case. $^{16}$

These results should, however, be interpreted in light of a change in survey protocol that appears to have affected the measurement of the decision-making variables, discussed briefly here and in detail in online Appendix A. In Wave 1 the household survey was administered to the household head while in Waves 2 and 3 the oldest female in the household was interviewed. Consequently, a higher percentage of older women are listed as the household head in Waves 2 and 3 compared to Wave 1 (online Appendix Table 4). Women are also more likely to be named as the decision-maker in Waves 2 and 3 because the household head variable is highly correlated with the decision-making variables. This correlation is certainly due in part to the true correlation between the household head and the decision-maker. However, it is also likely due to measurement error that results when the first person on the household roster is listed as the decisionmaker. This change in protocol has therefore increased the likelihood that all older women, regardless of pension-eligibility, are named as the decision-maker. This then makes any changes in decision-making due to pension-eligibility more difficult to detect. Overall, the consistently positive estimates for women in Waves 2 and 3 combined with the introduction of increased measurement error in the outcome variables is suggestive that similar changes in women's decision-making power are occurring in all

16. The coefficients on male and female eligibility are statistically different only in the linear specification for Wave 3 , and then only at the 10 percent level. 


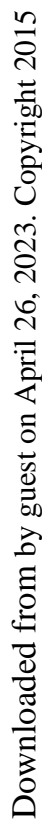

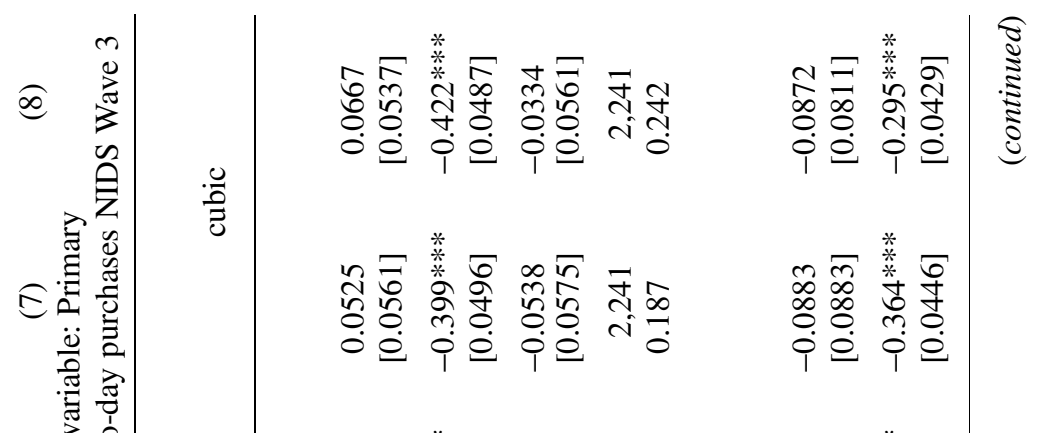

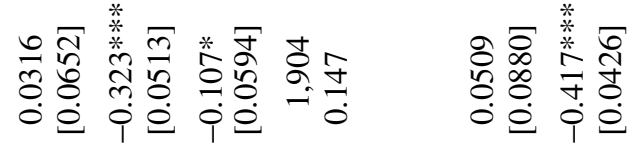

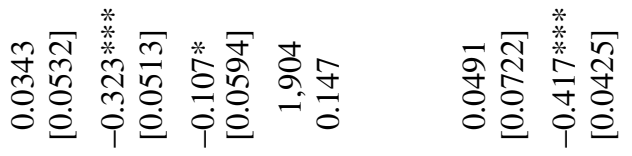

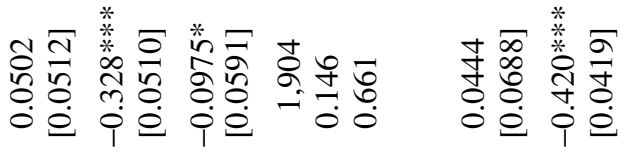

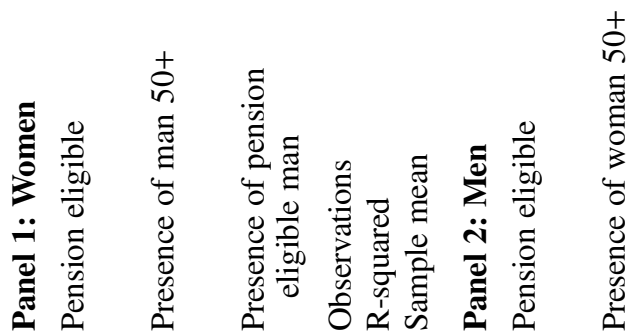




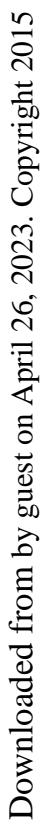

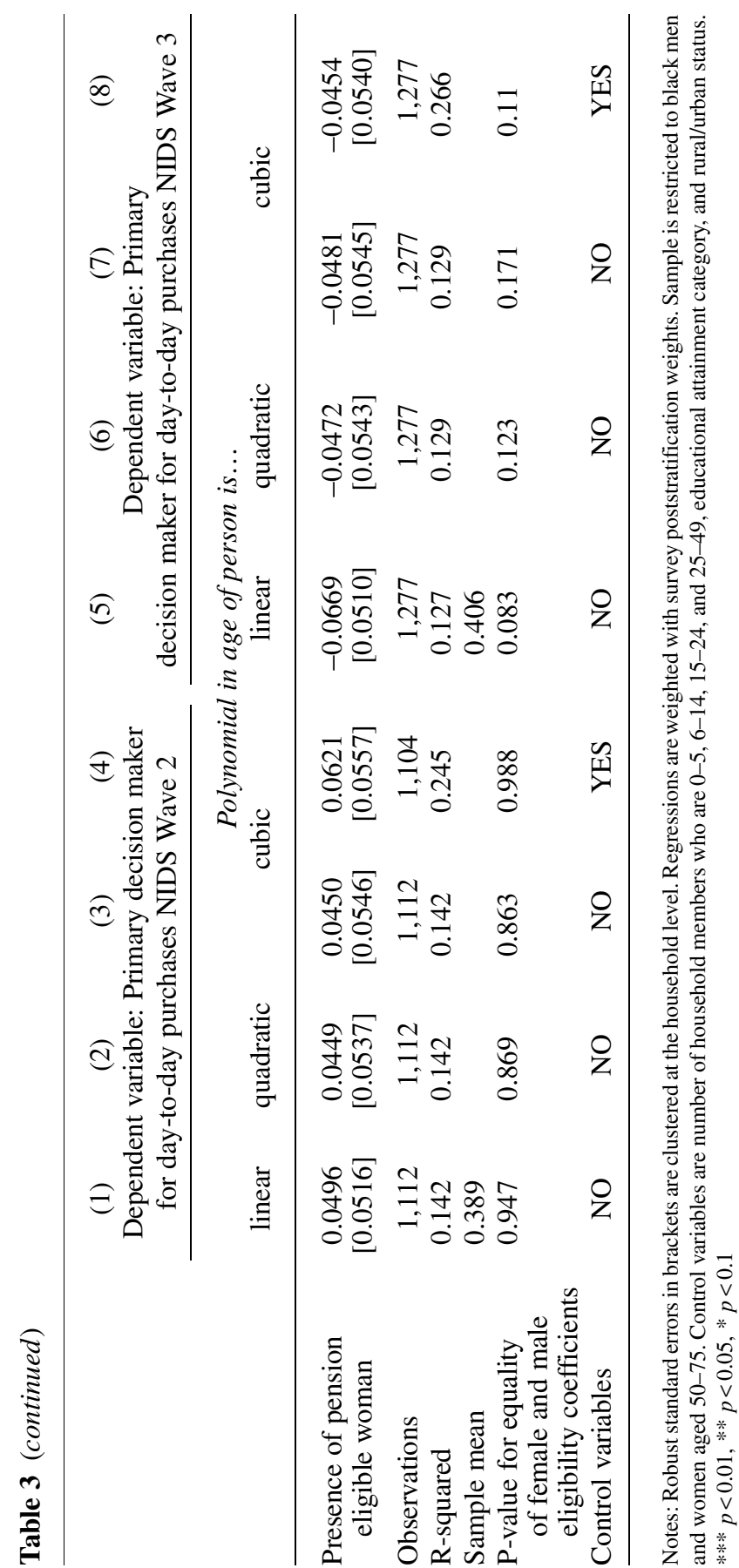


three survey rounds. However, all results should be interpreted with the caveat that I cannot show this robustly across waves.

\section{B. Impacts on Decision-Making Power of Other Household Members}

The result that women's decision-making power increases with pension-eligibility leads to the question of from whom in the household that power is coming. The fact that bargaining power appears to be following income controlled by women is an important economic finding but it also has substantial policy implications. For example, advocates for female empowerment may argue that this result is evidence in favor of expanding transfer programs but it is possible that this increase comes at the expense of other women in the household, leading to no overall increase in female bargaining power.

In the analysis that follows, I focus only on women for simplicity, as the previous analysis in Table 2 did not indicate that male decision-making power was changing with pension-eligibility. The first goal is to understand who in the household is a candidate to lose decision-making power when a woman becomes pension-eligible. I create five categories of potential decision-makers: women 50 and over, men 50 and over, women 18 to 49 , men 18 to 49 , and cases where the household does not agree on the identity of the decision-maker. Because these are household level designations, the data is presented at the household level. I focus only on households with women who are not yet pension-eligible (ages 50 to 59) because I want to understand who the decision-maker was prior to the eligibility of the older woman. The sample differs from the individuallevel analysis only in that households where there is more than one older woman of the same gender are collapsed into one observation. Fewer than 3 percent of households have more than one older person of the same gender.

Table 4 presents the percentages of households that fall into the different decisionmaking categories separately by whether an older male is present. Panel 1 presents results for the day-to-day purchases category and Panel 2 refers to all four categories. When no older male is present, women are the primary decision-makers in the large majority of households under both definitions of the variable. When an older man is present the distribution is more split between the older male and female, although men do dominate. Interestingly, younger adults play only a small part in decision-making. Cases of disagreement over who is the decision-maker is the other category of importance, especially in households where there is both an older woman and older man (24 percent for day-to-day purchases and 40 percent for all four categories).

Inow examine how the distribution of household decision-making power may change when a woman becomes pension-eligible. The specification that I employ is similar to that used to estimate changes on the individual level but because the outcomes are at the household level the sample is households with a woman aged 50 to 75 . I include a polynomial (linear, quadratic, and cubic) in the age of the oldest woman in the 50 to 75 age range and indicators for the presence of an older male and pension-eligible male. Standard errors are clustered at the survey cluster level. I focus on the two main competitor categories for decision-making power: a male 50 and over, and household disagreement over who is the decision-maker.

Table 5 presents the results. Panel 1 displays the results for decision-making over dayto-day purchases and Panel 2 the results for decision-making in all four categories. 


\title{
Table 4
}

Identity of Household Decision Maker in Non-Eligible Households

\author{
Households with a: \\ Woman 50-59 \\ No man \\ Man \\ $50+$ in hh \\ $50+$ in hh
}

\section{Panel 1: Decision maker refers to day-to-day purchases}

Decision maker is woman $50+$ (percent)

Decision maker is man $50+$ (percent)

Decision maker is woman 18-49 (percent)

Decision maker is man 18-49 (percent)

$3.1 \quad 0.0$

Household disagrees on decision maker (percent)

Observations

\section{Panel 2: Decision maker refers to all four categories}

Decision maker is woman $50+$ (percent)

Decision maker is man $50+$ (percent)

Decision maker is woman 18-49 (percent)

Decision maker is man 18-49 (percent)

Notes: Author's calculations from 2008 NIDS.

Columns 1 to 3 display results for whether or not an older male is the primary decisionmaker in households where an older male is present. The coefficient on female pensioneligibility estimates that men 50 or over are 10 to 14 percentage points less likely to be the primary decision-maker for day-to-day purchases and six to ten percentage points less likely be the decision-maker in all four categories when a woman becomes pensioneligible. The coefficient falls short of statistical significance but is suggestive of a negative impact on the decision-making power of older men. However, given the small sample size, it is difficult to draw any definitive conclusions.

Columns 4-9 examine the impact of pension-eligibility on disagreement over decision-making in the household separately by whether or not an older male lives in the household. In households with no older man (Columns 4-6), female pension-eligibility results in a nine to 14 percentage point decrease in household disagreement over the decision-maker for day-to-day purchases and a 14 to 22 percentage point decrease in household disagreement over the decision-maker in all four categories. This result is large relative to the sample means and the magnitude is somewhat sensitive to the degree of polynomial chosen, particularly in Panel 2 . However, it is highly statistically significant across specifications. There is no statistically significant reduction in disagreement in households with elderly men in Columns 7-9. This analysis suggests that when women do not live with an older male they are benefitting from increased certainty 


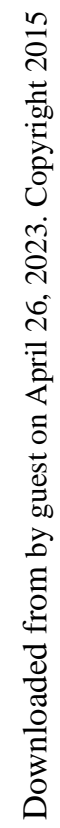

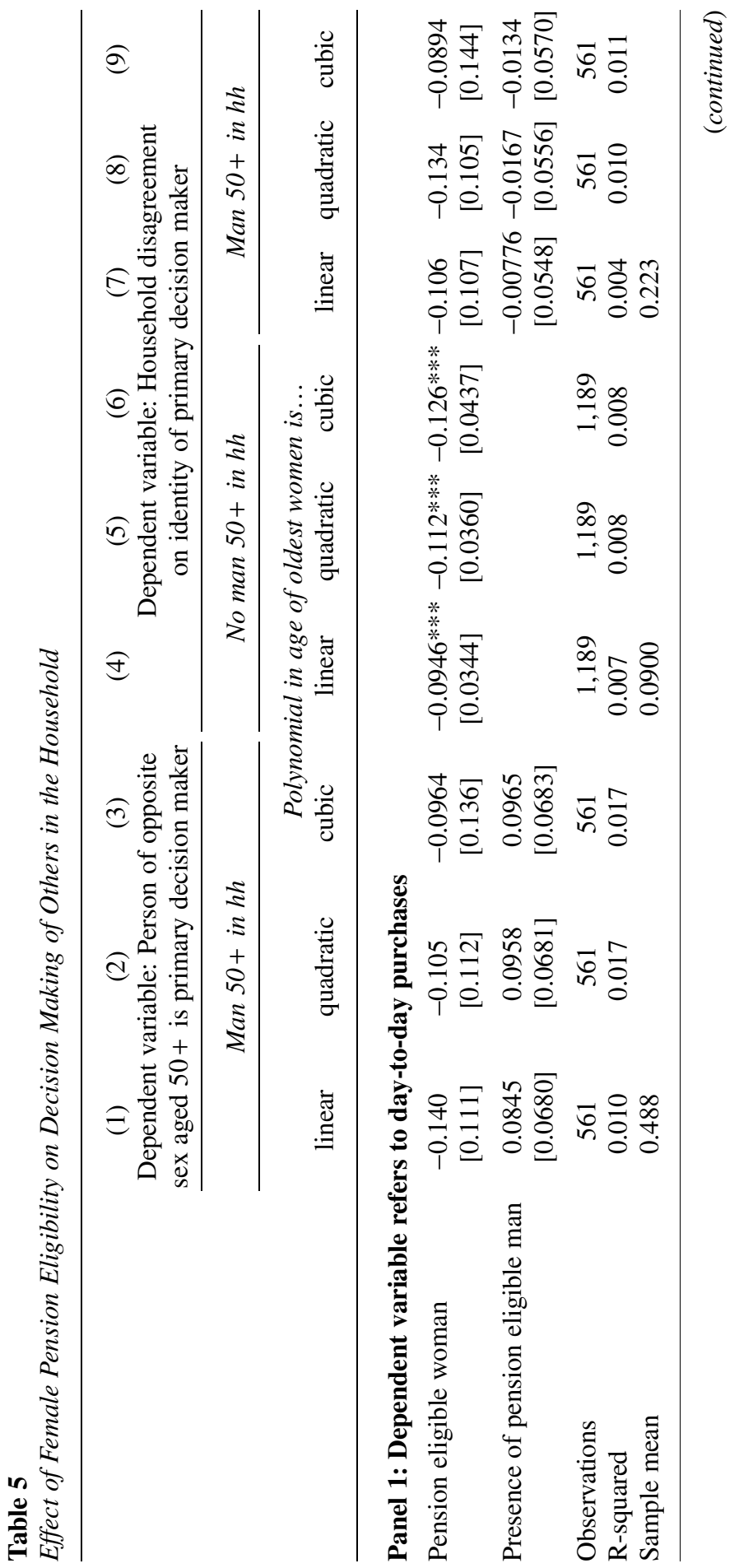


920

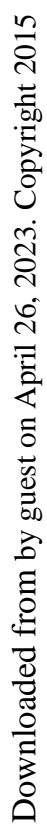

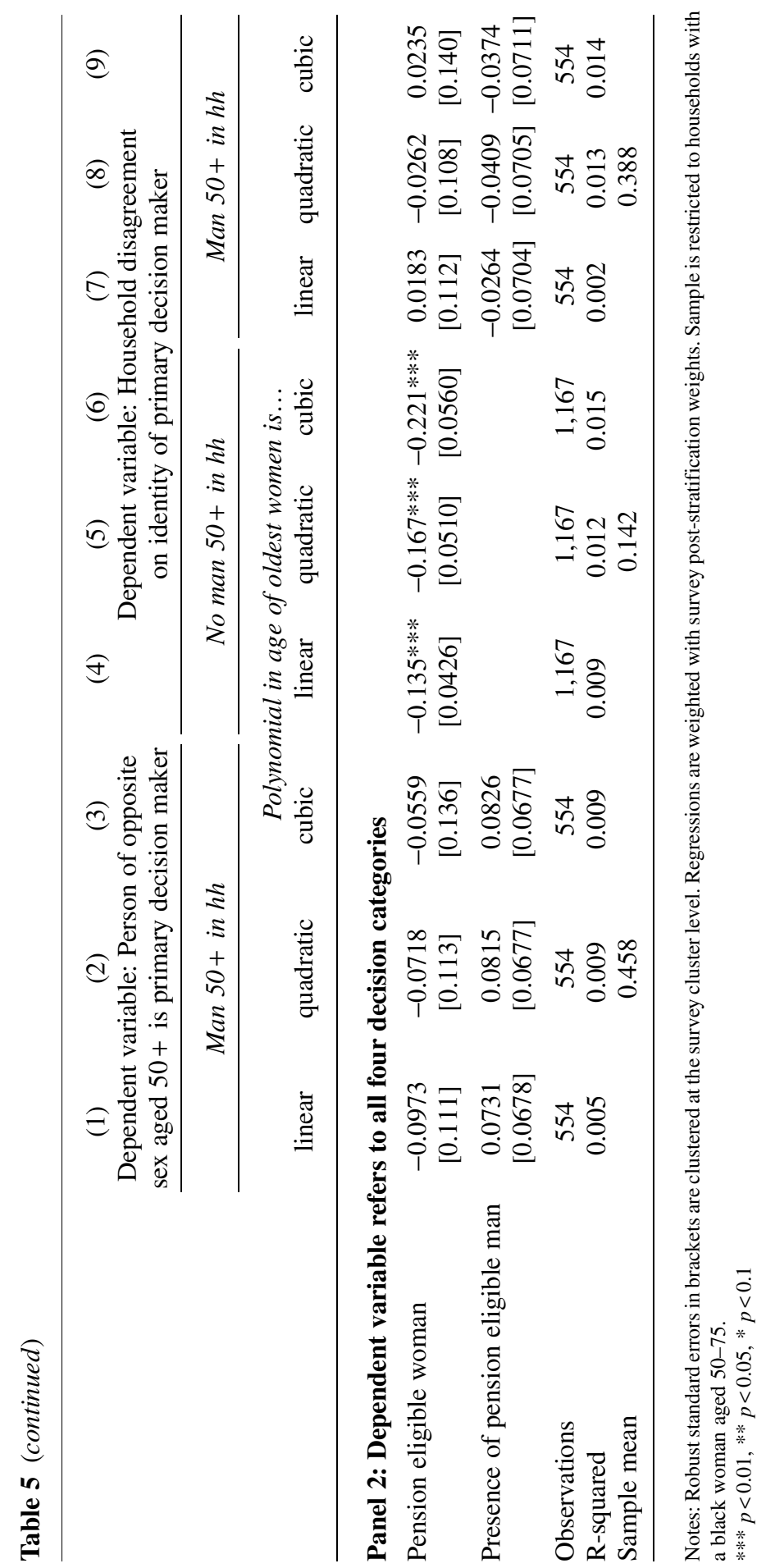


among household members about the identity of the decision-maker, an indication of increased bargaining power. In cases where the pension-eligible woman does live with an older man, there is suggestive evidence that the increase in her power is coming, at least in part, from a reduction in the decision-making power of older men.

\section{Pension-eligibility and Personal Income Share}

The household models that have informed the questions that this paper addresses are based on the assumption that bargaining power, and specifically individual income, affects decision-making in the household. Otherwise, the pension should not necessarily have an effect on how decisions are made in the household. However, if the interpretation of the result that women's decision-making power increases when they are pension-eligible is to be guided by these theories, then the nonresult in the case of pension-eligible men becomes puzzling. Given that men also experience a discontinuous increase in pension receipt at their age of eligibility (Figure 1b), this increase in income should also increase their decision-making power. ${ }^{17}$

It is instructive therefore to understand whether or not individual income is actually the channel through which the impact on female decision-making is operating. First, I examine whether individual income is correlated with decision-making in the household. Using the reports of individually earned income from the NIDS Wave 1 adult surveys, for each older adult I calculate his or her personal income share (the percentage of total household income that he or she reports individually including pension income). Figure 3 graphs the mean value of the primary decision-maker for day-to-day purchases indicator variable against this personal income share variable in five percentage point bins by gender. ${ }^{18}$ There is a clear relationship between income share and decisionmaking for both men and women, and the relationship holds regardless of pensioneligibility (not shown). ${ }^{19,20}$

This strong relationship between income share and decision-making power draws a clear line to why there are strong impacts of the pension on decision-making, at least for women. Consequently, we also should see a discontinuity in income share at the age of pension-eligibility. In Figure 4 I plot the mean of the elderly individual's income share by age and the regression line, again estimated on either side of the age discontinuity. Corresponding regression results are presented in Columns 1-4 of online Appendix Table 5. The discontinuity is clear and striking in the female sample and provides a convincing channel through which the increase in decision-making occurs. Statistical significance is confirmed by the regression results and the coefficient on eligibility is statistically significantly different for men and women. However, there is no clear increase at age 65 in

17. One possibility is that men were already the decision-makers prior to eligibility and thus there is no room for improvement. However, the statistics on decision-making in Table 1 make it clear that noneligible men though likely to be the decision-makers, are by no means always the decision-maker.

18. In Figures 3-5 I drop the top half percent of elderly male and female household income earners to eliminate several extreme outliers. Dropping the outliers is done only to allow for cleaner presentation of results and does not affect the qualitative implication of the figures.

19. The relationship holds in the entire NIDS sample, not just the elderly population.

20. To avoid losing observations to missing income data, I utilize income data with imputations done by NIDS.

Dropping observations with imputations does not affect the results. 

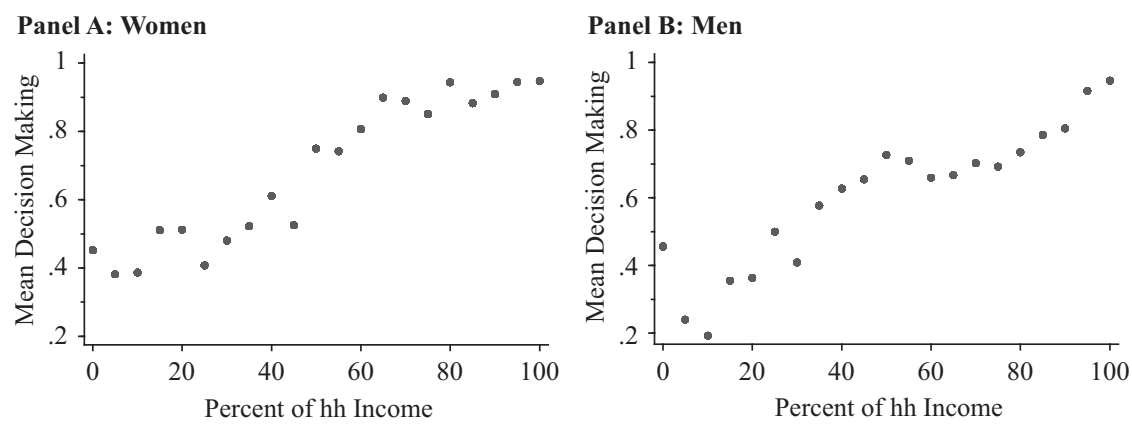

\section{Figure 3}

\section{Decision-making by Percent of Personal Income Share}

Notes: Sample is individuals aged 50 to 75, women in Panel A and men in Panel B. The top half percent of male and female household income is trimmed. Scatterplots are the mean of whether or not everyone in the household agrees the individual is the primary decision-maker for day-to-day purchases by five percentage point bins of personal income share.

the male sample, and the estimated regression coefficients are small, negative, and not statistically significant. This pattern of increased personal income share with female eligibility is additionally repeated in NIDS Waves 2 and 3 (Wave 2 results are in Columns 1-3 of Table 6 . Wave 3 results not shown). This robustness to survey wave is important as income measurement should not be vulnerable to the changes in survey protocols that have affected the decision-making variable. If household decision-making is determined in part through income control, then this lack of increase in men's income share provides an explanation for why there is no increase in male decision-making. This same pattern is evident, although noisier, when examining raw individual income (results not shown).

The idea that increased income share is driving the increase in decision-making power is bolstered by an examination of the income shares of others in the household. Recall the suggestive evidence in Table 5 that in households where an older woman is living with an older man the increase in female decision-making power comes at least in part from a reduction in the decision-making power of older men. Similarly, I can show that in those same households the personal income share of older men drops with female eligibility (online Appendix Figure 3). ${ }^{21}$

Although the lack of increase in male income share provides a convincing explanation for why there is not an increase in male decision-making, it is perplexing given the fact that there is a discontinuity in male pension receipt at 65 . If male income is not increasing, where is the pension money going? Given previous evidence that both men and women exit the labor force in large numbers at the age of eligibility (Lam et al. 2006;

21. A more direct way to show the relationship between personal income share and decision-making power would be to use pension-eligibility as an instrument for personal income share in a regression of decisionmaking power on income share. However, given the wide range of ways in which the pension can impact households, the exclusion restriction of such an instrument would surely be violated. 

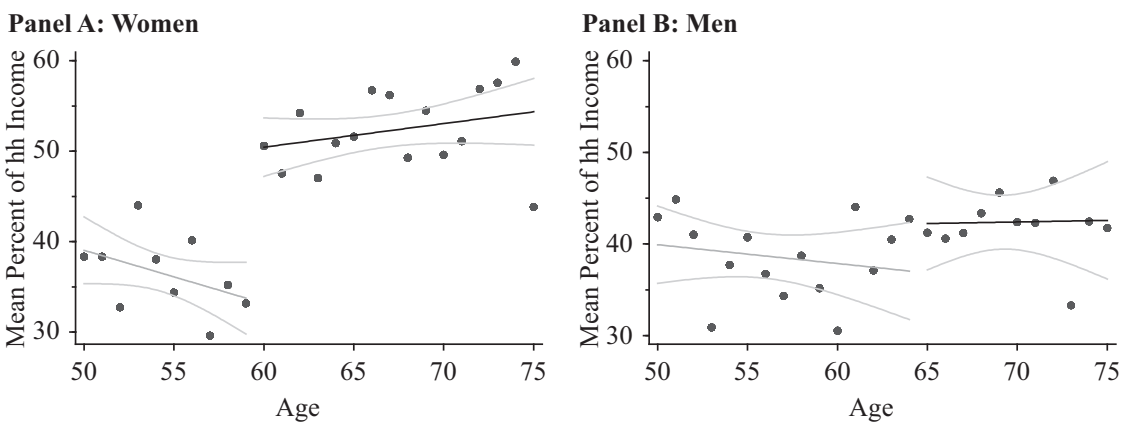

\section{Figure 4}

\section{Personal Income Share by Age}

Notes: Sample is individuals aged 50 to 75, women in Panel A and men in Panel B. The top half percent of male and female household income is trimmed. Scatterplots are unweighted means of Y-axis variable by age. Unweighted OLS regression lines of Y-axis variable on age are estimated on either side of the discontinuity (age 60 for women and age 65 for men). Ninety-five percent confidence intervals are shown around the regression lines. Y-axis variable is the percent of total household income reported to be received by the individual.

Ranchhod 2006), one explanation is that the pension income received by men is cancelled out by a reduction in labor income. However, given that the drops in employment were found for both men and women, it is not immediately clear why this cancelling out would occur for one gender and not the other. ${ }^{22}$

An examination of labor income is more instructive than a simple examination of employment. Figure 5 graphs the age trend, separately by gender, for individual labor income as a percentage of household, nonpension, income. ${ }^{23}$ The graphical results are confirmed in regression results presented in Columns 5-8 of online Appendix Table 5. Strong discontinuities are present for both genders but the means prior to pensioneligibility and the size of the drop at the age of eligibility are much smaller for women than they are for men. While I do not have the power to statistically reject that the declines at eligibility are the same for men and women, male labor income prior to eligibility was a more important part of the household budget than female labor income. Therefore, while the pension represents an increase over what women were earning, it may be more of a replacement for what men previously received. This can explain why men do not see an increase in personal income share when they become pension-eligible, and consequently why there is no subsequent increase in their decision-making power in the household.

22. 43 percent and 16 percent of noneligible and eligible women respectively are working. 54 percent and 21 percent of noneligible and eligible men respectively are working. It is interesting to note that labor force withdrawal is not a requirement for pension receipt for most people as employment income in this population is generally below the means test for eligibility.

23. I perform the calculation in this way to mitigate the mechanical decrease in labor income as a percentage of household income if household income were to increase with the pension. 
924

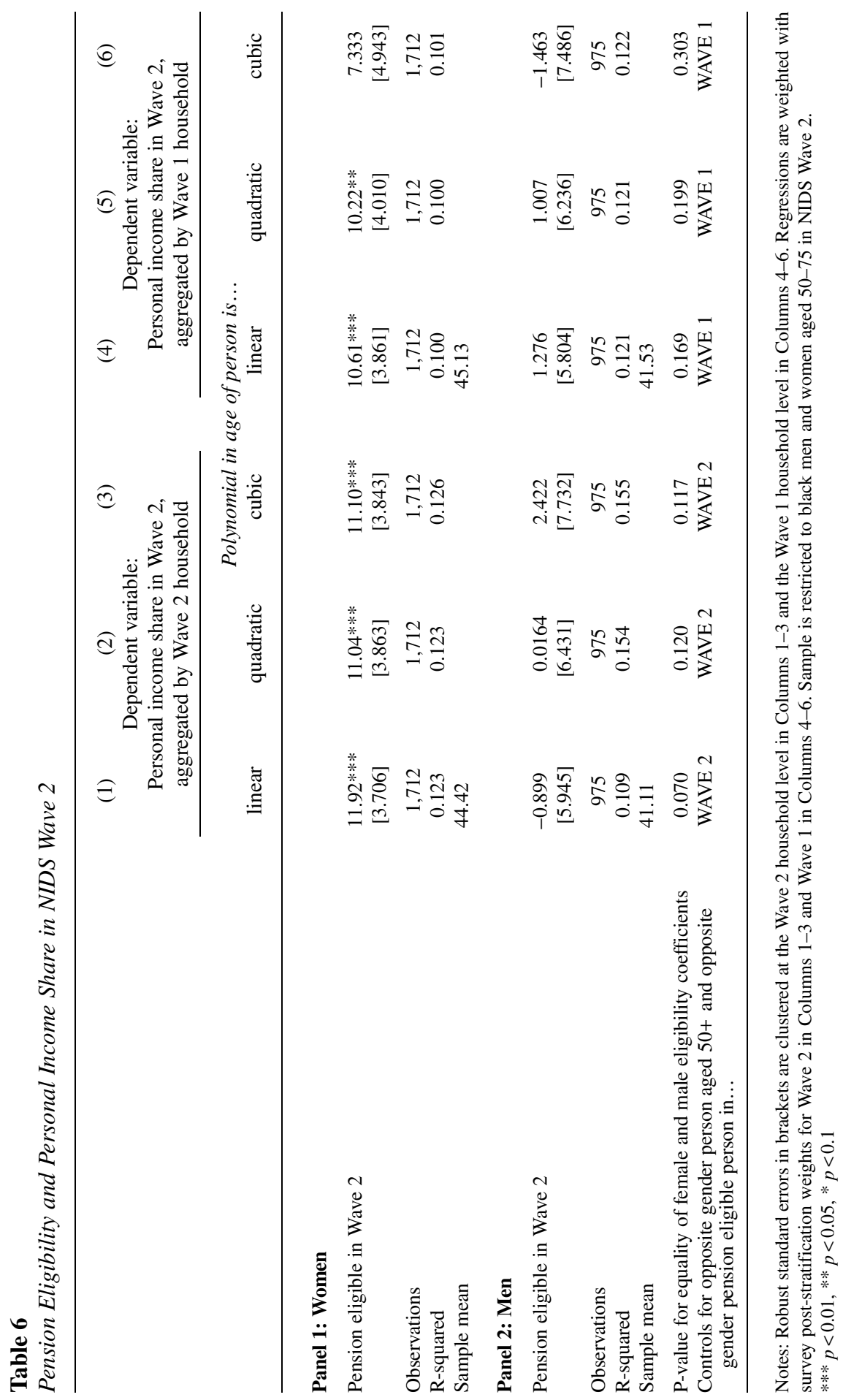

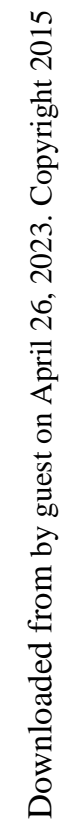



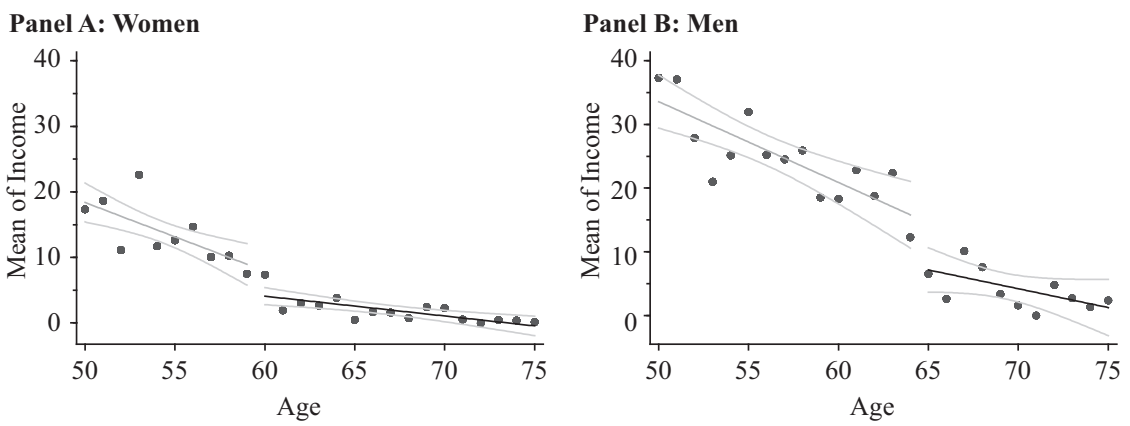

\section{Figure 5}

\section{Individual Labor Income as Percent of Household Nonpension Income by Age}

Notes: Sample is individuals aged 50 to 75, women in Panel A and men in Panel B. The top half percent of male and female household income is trimmed. Scatterplots are unweighted means of Y-axis variable by age. Unweighted OLS regression lines of Y-axis variable on age are estimated on either side of the discontinuity (age 60 for women and age 65 for men). Ninety-five percent confidence intervals are shown around the regression lines. Y-axis variable is individual labor income as a percent of household nonpension income.

Given this labor income response, it is important to consider whether differential changes in total household income are driving the main results. In other words, if total household income goes up by more with female eligibility than with male eligibility and if increased household income tends to increase women's decision-making power, then it is not clear whether the results in Table 2 are specific to the identity of the recipient or simply a result of increased household income. To address this issue in online Appendix Table 6 I examine the effect of male and female eligibility on total household monthly income using the same household-level sample and estimation strategy described in Table 5. The dependent variable in Columns 1-4 is monthly income in levels and the dependent variable in Columns 5-8 is log monthly income.

The results of the analysis are noisy; the coefficients are positive but are not consistently statistically significantly different from zero. Importantly, the male and female coefficients are not statistically significantly different in any specification, and the magnitude of the male coefficients is generally larger than that of the female coefficients. Although based only on the labor income analysis one would predict a larger increase in household income with female eligibility relative to male eligibility, other responses to the pension within the household suggested by previous research could also impact total household income. This includes, for example, adjustments in the labor supply of prime age adults (Bertrand, Mullainathan, and Miller 2003) or reductions in transfers from other households (Jensen 2003). Addressing the full range of these responses is beyond the scope of this paper, but the evidence presented here suggests that the decision-making results are not driven by an income effect in households with female pension recipients.

This investigation of changes in labor income provides a straightforward explanation for why the pension results in changes in decision-making power for women but not for men. However, it is important to acknowledge that this explanation necessarily simplifies some of the complex dynamics occurring within the household. Leaving the labor force is ultimately a choice that both men and women make with the knowledge that 
reduced earnings will negatively affect their bargaining power. In making this choice pension recipients are essentially revealing that they prefer leisure to increased bargaining power. While this is an interesting pattern of behavior, it does not alter the main conclusion of the paper, that increased control of household resources increases the capacity to influence decisions.

An alternative way to conceptualize this issue is to think of different domains of decision-making and imagine that men are simply using their increased bargaining power to make decisions about household time allocation. Unfortunately, the NIDS survey does not ask about decision-making over household labor supply and time allocation, and therefore I cannot speak directly to this issue. However, the high level of correlation between the four domains that are on the survey suggests that there is not a large role for substantial differences in decision-making power across domains. If the pension is altering male bargaining power, it is doing so in such a way that is not reflected by the decision-making or income measures on the NIDS survey.

\section{Discussion}

This analysis of how pension-eligibility affects decision-making and income share in the household is interesting largely because we expect these changes to translate into changes in measures of well-being in the household. In analysis presented in detail in online Appendix B, I show that female, but not male, pension-eligibility is associated with improvements in nutritional indicators for young girls (as in Duflo 2003) and increased ownership of consumer durables. Empirical analyses such as these that find positive impacts on household outcomes associated with increases in female resources but no such benefits associated with increases in male resources are often used to argue that cash transfers may be more productively used when given to women instead of men. However, when taken together with the income share results described in Section V the interpretation is not as clear. Given that there is no increase in male income or income share with male pension-eligibility there is no a priori reason to expect to see positive impacts on household well-being as in the case of female eligibility. There may have been positive impacts if male income had increased.

The results in this study highlight the need for caution when interpreting results that may indicate that money should be given to women. It is true that men choose to spend the pension on retirement, but women, to the extent that they were previously working, do that as well. Given that labor force participation is declining rapidly around the age of eligibility, the pension acts to protect the household from the negative consequences of the household member's eventual retirement. Even if the narrow goal of a transfer is an improvement in child nutrition, it is not possible to predict what would have happened had the transfers been given to, for example, younger men and women less likely to leave the labor force. Indeed, in a study in Burkina Faso, Akresh, de Walque, and Kazianga (2012) find that conditional cash transfers have the same positive effects on the utilization of preventative health services when given to the father as when given to the mother. ${ }^{24}$

24. Also related Benhassine et al. (forthcoming) find that cash transfers have similar effects on school attendance when given to the mother and when given to the father. 

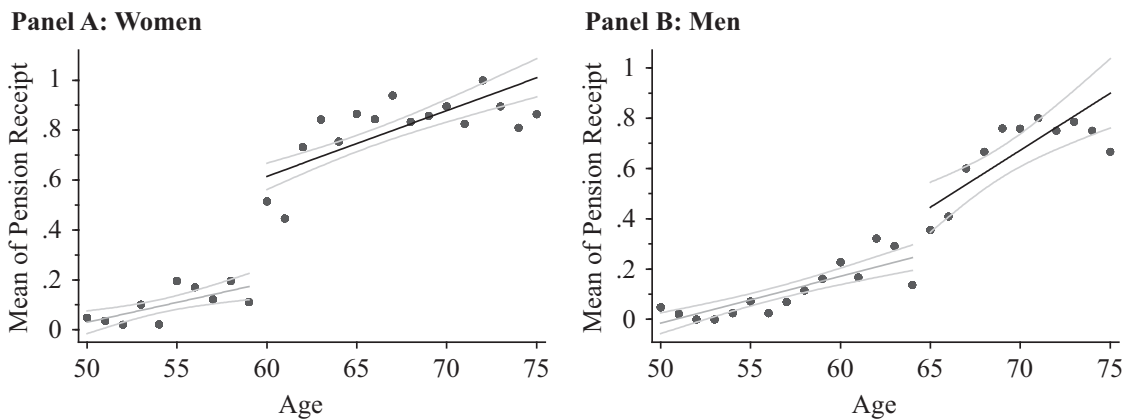

\section{Figure 6}

\section{Pension Receipt by Age in 1993: Households with Young Children}

Notes: Scatterplots are unweighted means of Y-axis variable by age in years. Unweighted OLS regression lines of Y-axis variable on age are estimated on either side of the discontinuity (age 60 for women and age 65 for men). Ninety-five percent confidence intervals are shown around the regression lines. Source is 1993 PSLSD data set. Sample is individuals aged 50 to 75 living with a child 6 to 60 months. Y-axis variable is pension receipt.

Given that the Duflo (2003) study on pension-eligibility and child health is one of the papers most widely cited in support of the contention that transfer programs should be directed toward women, it is interesting to examine the income dynamics in the data used in that study. The analysis in that paper was done using the Project for Statistics on Living Standards and Development (PSLSD), a 1993 survey similar to NIDS, although it consisted only of a single household level survey. Using the PSLSD data I construct Figures 6 and 7. Figure 6 shows that the discontinuity in pension receipt in 1993 does exist at age 60 and 65 for women and men respectively, although it is smaller than in 2008, particularly for men. Figure 7 is analogous to Figure 4 from the NIDS data examining the changes in personal income share as a result of male and female eligibility. I do this only for older people who live with a child 6 to 60 months old, as that is the sample of interest in Duflo's paper. ${ }^{25}$ Decision-making data was not collected in the PSLSD. The results are confirmed with regression analysis in online Appendix Table 9.

The results of this analysis roughly replicate the results in the NIDS data. A strong increase in personal income share (Figure 7) is present for pension-eligible females, but not for pension-eligible males, suggesting that women experience an increase in bargaining power when they become pension-eligible while men may not. ${ }^{26,27}$ The pension, in both 1993 and 2008, appears to leave men's status in the household unchanged,

25. As in Section V, I drop observations in the top half percent of household income.

26. Additionally, there is no increase in household income with female or male eligibility (results not shown), indicating that the observed changes in nutrition must be due to shifts in female bargaining power, not increased household income.

27. It should be noted that in the 1993 data I cannot reject that the coefficients on male and female eligibility in Columns 4-6 are equal. 

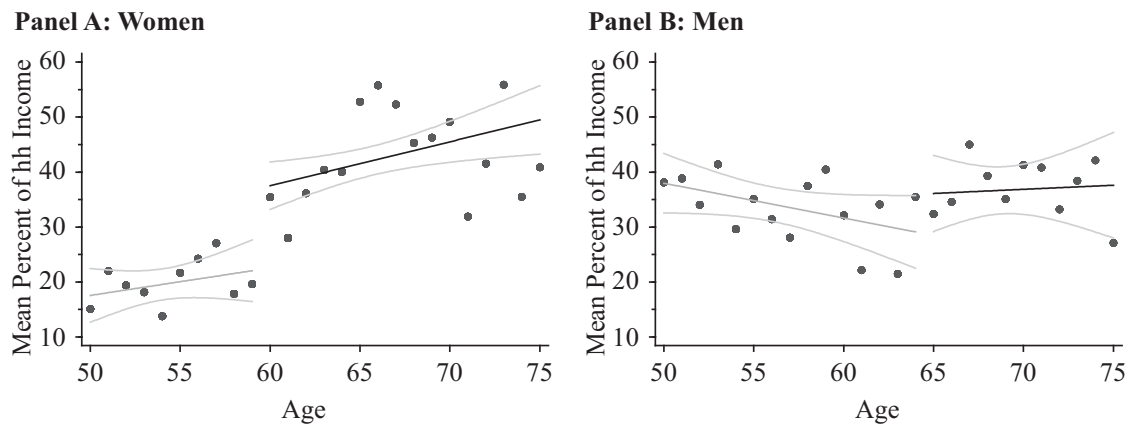

\section{Figure 7}

\section{Personal Income Share by Age in 1993: Households with Young Children}

Notes: Scatterplots are unweighted means of Y-axis variable by age in years. Unweighted OLS regression lines of Y-axis variable on age are estimated on either side of the discontinuity (age 60 for women and age 65 for men). Ninety-five percent confidence intervals are shown around the regression lines. Source is 1993 PSLSD data set. Sample is individuals aged 50 to 75 living with a child 6 to 60 months. Y-axis variable is the percent of total household income reported to be earned or received by the individual.

and these results therefore suggest care if extrapolating the Duflo paper to make policy recommendations outside of its specific context (transfers to the elderly and changes in child nutrition).

\section{Changes in Household Composition}

The most important threat to the validity of the results in this paper is that receipt of the pension causes households to reorganize and consequently-that the results are an artifact of this change in household structure rather than a direct impact of the pension itself. Families are likely to share resources and make decisions with family members beyond just those with whom they are co-resident, but the survey questions do not consider income from nonresident family members or allow for them to be named as decision-makers. For example, the literature finds increases in the numbers of young children and young woman and decreases in prime working age adults with female pension-eligibility (Edmonds et al. 2005; Ardington, Case, and Hosegood 2009). If prime-age income earners are leaving the household their income will not be captured in the NIDS survey, removing it from the denominator of the income share calculation but possibly not from the true family budget. Additionally, these earners still may participate in family decision-making although they cannot be named as such on the survey, possibly leading to an increase in the decision-making power of older women that is, in fact, spurious. ${ }^{28}$

28. There is also evidence that prime-age adults living with pensioners are negatively selected (Hamoudi and Thomas 2014), which may make them less likely to be decision-makers. 
Investigating how household re-arrangement may affect my results is then a critical component to their validity. A key observation is that if, as the literature suggests, the most likely people to leave a household when someone becomes pension-eligible are prime-age adults, then this is not likely to be the principal driver of the main decisionmaking results. Table 4 shows that in households with an elderly woman who is not yet pension-eligible, prime-age adults are almost never named as the primary decisionmaker for either definition of the variable. In order for the large increase in decisionmaking power of elderly women to be driven by the departure of these prime-age adults, they would have to have been named as decision-makers in the not-yet eligible households in much larger numbers. However, given that disagreement over the identity of the decision-maker is a category of importance, it is still possible that the reduction of the potential candidates for the decision-maker led to increased agreement rather than true solidification of the pension-eligible women as the decision-maker.

Although NIDS is a panel study where individuals are tracked from wave to wave, because my analysis has focused on the first wave, I cannot track changes in households prior to that survey. However, I can use the second wave of the survey to analyze changes between Wave 1 and Wave 2, under the assumption that household reorganization patterns for individuals who are pension-eligible in Wave 1 are similar to the patterns for those who are eligible in Wave 2. Because the results for personal income share are similar in Waves 1 and 2, this result is particularly appropriate to examine using the Wave 2 data.

To account for the fact that the pension may have caused income earners to leave the household, I conduct the same analysis of pension-eligibility on personal income share as in Section V but aggregate household income based on where the older person lived in Wave 1 instead of in Wave $2 .{ }^{29}$ Table 6 presents the results. Columns $1-3$ show the Wave 2 results aggregated by Wave 2 household and Columns 4-6 show the Wave 2 results aggregated by Wave 1 household. The results for women are in panel 1 and for men in Panel 2.

The standard Wave 2 results in the first three columns show a similar pattern to the same results in Wave 1, large and statistically significant across specifications. The results aggregated by Wave 1 household are similar, attenuated only slightly in the linear and quadratic specifications. The cubic specification yields a smaller point estimate that falls short of statistical significance. The estimates for men are small and not statistically significant. However, I am unable to reject that the male and female eligibility coefficients are equal. Despite this, the stability of the coefficients when aggregating by Wave 1 instead of Wave 2 household strongly suggests that changes in household composition are not the main driver of the income share results this paper finds. ${ }^{30}$ Unfortunately, the data do not allow for a similar analysis that directly utilizes the decision-making variables. However, the strong correlation between decision-making and income share does suggest that one result should follow the other. Given the critical importance of this issue, I provide further analysis in online Appendix C, all of which suggests that my results are robust to changes in household composition.

29. I thank an anonymous referee for this excellent suggestion.

30. Because of attrition between Waves 1 and 2, approximately 4 percent of the sample in Table 6 lived with an adult aged 18-49 in Wave 1 who was not interviewed in Wave 2. Consequently, income data for these adults is not available in Wave 2. Dropping these households from the analysis does not affect the results (results not shown). 


\section{Conclusion}

The results in this study show that women experience an increase in personal income share when they become pension-eligible. Collective models of the household predict that this increase should result in an increase in bargaining power, and I find that eligible women are more likely to be the primary decision-maker in their households across a variety of categories. This is one of the first studies to show how specific mechanisms within the household (namely decision-making) are reacting to gender specific changes in income instead of relying solely on the reduced form impact on household outcomes to make arguments about bargaining power.

Corresponding improvements in household outcomes with female, but not male, eligibility echo previous results that have been used to support nonunitary models of the household and to argue that social programs should channel resources to women. The findings in this paper that the lack of impacts for men may be due to the lack of increase in male decision-making power suggest caution in advocating for such targeting based on a reduced form analysis alone. Any evaluation of a cash transfer program such as the South African pension should acknowledge that households will react in complex ways and changes in outcomes cannot be interpreted in the absence of an understanding of changes in intrahousehold income dynamics.

\section{References}

Abel, Martin. 2013. "Unintended Labor Supply Effects of Cash Transfer Programmes: Evidence from South Africa's Old Age Pension.” SALDRU Working Paper Series 114.

Akresh, Richard, Damien de Walque, and Harounan Kazianga. 2012. "Alternative Cash Transfer Delivery Mechanisms: Impacts on Routine Preventative Health Clinic Visits in Burkina Faso." NBER Working Paper 17785.

Anderson, Siwan, and Mukesh Eswaran. 2009. "What Determines Female Autonomy? Evidence from Bangladesh.” Journal of Development Economics 90(2):179-91.

Ardington, Cally, Anne Case, and Victoria Hosegood. 2009. "Labor Supply Responses to Large Social Transfers: Longitudinal Evidence from South Africa." American Economic Journal: Applied Economics 1(1):22-48.

Ashraf, Nava, Dean Karlan, and Wesley Yin. 2009. "Female Empowerment: Impact of a Commitment Savings Product in the Philippines." World Development 38(3):333-44.

Banerjee, Abhijit, Esther Duflo, Rachel Glennerster, and Cynthia Kinnan. 2015. "The Miracle of Microfinance? Evidence from a Randomized Evaluation.” American Economic Journal: Applied Economics 7(1):22-53.

Becker, Gary. 1974. “A Theory of Social Interactions.” Journal of Political Economy 82(6): 106394.

1981. A Treatise on the Family. Cambridge, Mass.: Harvard University Press, enlarged edition 1991.

Benhassine, Najy, Florencia Devoto, Esther Duflo, Pascaline Dupas, and Victor Pouliquen.

"Turning a Shove into a Nudge? A "Labeled Cash Transfer" for Education." American Economic Journal: Economic Policy. Forthcoming.

Bertrand, Marianne, Sendhill Mullainathan, and Douglas Miller. 2003. "Public Policy and Extended Families: Evidence from Pensions in South Africa." The World Bank Economic Review 17(1):27-50. 
Browning, Martin, Pierre-André Chiappori, and Yoram Weiss. 2014. Economics of the Family. New York, N.Y.: Cambridge University Press.

Case, Anne, and Angus Deaton. 1998. "Large Cash Transfers to the Elderly in South Africa." Economic Journal 108(450):1330-61.

Chiappori, Pierre-André. 1988. "Rational Household Labor Supply.” Econometrica 56(1):63-89.

- 1992. "Collective Labor Supply and Welfare." Journal of Political Economy 100(3):437_ 67.

De Carvalho Filho, Irineu Evangelista. 2012. "Household Income as a Determinant of Child Labor and School Enrollment in Brazil: Evidence from a Social Security Reform.” Economic Development and Cultural Change 60(2):399-435.

De la Brière, Bènèdicte, and Agnes Quisumbing. 2000. "Final Report: The Impact of Progresa on Women's Status and Intrahousehold Relations." IFPRI report.

Doss, Cheryl. 2013. "Intrahousehold Bargaining and Resource Allocation in Developing Countries." World Bank Research Observer 28(1):52-78.

Duflo, Esther. 2000. "Child Health and Household Resources in South Africa: Evidence from the Old Age Pension Program." The American Economic Review Papers and Proceedings 90(2): 393-98.

- 2003. "Grandmothers and Granddaughters: Old-Age Pensions and Intra-household Allocation in South Africa." The World Bank Economic Review 17(1):1-25.

- 2012. "Women's Empowerment and Economic Development." Journal of Economic Literature 50(4):1051-79.

Edmonds, Eric V., Kristen Mammen, and Douglas Miller. 2005. "Rearranging the Family? Income Support and Elderly Living Arrangements in a Low-Income Country." Journal of Human Resources 40(1):186-207.

Edmonds, Eric V. 2006. "Child Labor and Schooling Responses to Anticipated Income in South Africa." Journal of Development Economics 81(2):386-414.

Gelman, Andrew, and Guido Imbens. 2014. "Why High-Order Polynomials Should Not be used in Regression Discontinuity Designs.” NBER Working Paper No. 20405.

Hamoudi, Amar, and Duncan Thomas. 2014. "Endogenous Co-Residence and Program Incidence: South Africa's Old Age Pension.” Journal of Development Economics 109:30-7.

Jensen, Robert T. 2003. "Do Private Transfers 'Displace' the Benefits of Public Transfers? Evidence from South Africa." Journal of Public Economics 88(1-2):89-112.

Lam, David, Murray Leibbrandt, and Vimal Ranchhod. 2006. "Labor Force Withdrawal of the Elderly in South Africa." In Aging in Sub-Saharan Africa: Recommendations for Furthering Research, ed. Barney Cohen and Jane Menken, 214-49. Washington, D.C.: National Academies Press.

Lee, David S., and Thomas Lemieux. 2010. "Regression Discontinuity Design in Economics." Journal of Economic Literature 48(2):281-355.

Lundberg, Shelly, and Robert A. Pollack. 1993. "Separate Spheres Bargaining and the Marriage Market." Journal of Political Economy 101(6):988-1010.

_ 1994. "Non-Cooperative Bargaining Models of Marriage." American Economic Review Papers and Proceedings 84(2):132-37.

- 1996. "Bargaining and Distribution in Marriage." Journal of Economic Perspectives 10 (4):139-58.

Lundberg, Shelly, Robert A. Pollack, and Terence J. Wales. 1996. "Do Husbands and Wives Pool Their Resources? Evidence from the United Kingdom Child Benefit." Journal of Human Resources 32(3):463-80.

Majlesi, Kaveh. 2014. "Labor Market Opportunities and Women's Decision-making Power Within Households.” Lund University Department of Economics Working Paper 2014:4.

Manser, Marilyn, and Murray Brown. 1980. "Marriage and Household Decision-Making: A Bargaining Analysis.” International Economic Review 21(1):31-44. 
McElroy, Marjorie B., and Mary Jean Horney. 1981. "Nash Bargained Household Decisions." International Economic Review 22(2):333-49.

McEwan, Hayley, Catherine Kannemeyer, and Ingrid Woolard. 2009. "Social Assistance Grants: Analysis of the NIDS Wave 1 Data set." NIDS Discussion Paper No. 10.

Ponczek, Vladimir. 2011. "Income and Bargaining Effects on Education and Health in Brazil." Journal of Development Economics 94(2):242-53.

Posel, Dorrit, James A. Fairburn, and Frances Lund. 2006. "Labour Migration and Households: A Reconsideration of the Effects of the Social Pension on Labour Supply in South Africa." Economic Modelling 23(5):836-53.

Qian, Nancy. 2008. "Missing Women and the Price of Tea in China: The Effect of Sex-specific Earnings on Sex Imbalance." Quarterly Journal of Economics 123(3):1251-85.

Ranchhod, Vimal. 2006. "The Effect of the South African Old Age Pension on Labour Supply of the Elderly." South African Journal of Economics 74(4):725-44.

Samuelson, Paul A. 1956. "Social Indifference Curves." Quarterly Journal of Economics 70(1): $1-22$.

South Africa Labour and Development Unit. 1993. "The Project for Statistics of Living Standards and Development." http://www.saldru.uct.ac.za/home/index.php?/PSLSD/pslsd accessed February 5, 2010. National Income Dynamics Study 2008, Wave 1 [data set]. Version 5.2. Cape Town: Southern Africa Labour and Development Research Unit [producer], 2009. Cape Town: DataFirst [distributor], 2014.

- National Income Dynamics Study 2010-2011, Wave 2 [data set]. Version 2.2. Cape Town: Southern Africa Labour and Development Research Unit [producer], 2014. Cape Town: DataFirst [distributor], 2014.

. National Income Dynamics Study 2012, Wave 3 [data set]. Version 1.2. Cape Town: Southern Africa Labour and Development Research Unit [producer], 2014. Cape Town: DataFirst [distributor], 2014.

SouthAfrica.info. 2008. "South Africa Men Get State Pensions Earlier." July 16. www.southafrica. info/services/government/pension-160708.htm.

Thomas, Duncan. 1990. "Intrahousehold Resource Allocation: An Inferential Approach.” Journal of Human Resources 25(4):635-64.

1994. "Like Father, Like Son; Like Mother, Like Daughter: Parental Resources and Child Height." Journal of Human Resources 29(4):950-88.

World Health Organization. 2006. WHO Child Growth Standards: Length/height-for-age, weightfor-age, weight-for-length, weight-for-height and body mass index for age: Methods and development. Geneva: World Health Organization. 